ISSN: $1130-3743$

\title{
LA EDUCACIÓN MORAL ANTE EL RETO DE LA POBREZA
}

\section{The challenge of poverty for the moral education}

\section{L'éducation morale devant le défi de la pauvreté}

Juan Escámez SÁnchez, Rafaela García LóPez y Cruz Pérez Pérez

Universidad de Valencia. Facultad de Filosofía y Ciencias de la Educación.

Departamento de Teoría de la Educación. Avda. Blasco Ibáñez, 30. 46020 Valencia.

Correo-e: juan.escamez@uv.es; rafaela.garcia@uv.es; cruz.perez@uv.es

Fecha de recepción: diciembre de 2003

Fecha de aceptación definitiva: marzo de 2004

BIBLID [(1130-3743) 15, 2003, 185-212]

RESUMEN

El artículo trata de la pobreza en el mundo, especialmente de la pobreza severa, y el reto que presenta a la educación moral. En la actualidad, el problema de la pobreza es abordado en el contexto del desarrollo humano; así se hace en el artículo, pero manteniendo la pobreza como centro de análisis y propuestas pedagógicas. Se parte de la situación de la pobreza al año 2003, de la Declaración del Milenio de las Naciones Unidas del año 2000, consensuada por 189 jefes de Estado o Gobierno, para erradicar la pobreza severa. Se hace una valoración ética de tales acontecimientos y se exponen los compromisos que ha de asumir la educación moral ante ellos. Se expone el papel central de las prácticas morales en la transformación moral de la vida pública, en los asuntos referentes a la pobreza, y la formación de la personalidad moral de los estudiantes. Por último, atendiendo al Informe del PNUD, 2003, Los Objetivos de Desarrollo del Milenio: un pacto entre naciones para eliminar la pobreza, se hacen cinco propuestas de prácticas morales para que los estudiantes adquieran competencias referidas a la erradicación de la lacra moral y política de la 
pobreza. Tales propuestas pedagógicas están referidas: al desarrollo sostenible, la cooperación internacional, el consumo justo y responsable, la participación en movimientos de servicio voluntario a la sociedad y la participación política.

Palabras clave: pobreza, desarrollo humano, educación moral, prácticas morales, participación política.

SUMMARY

The article is about the world poverty, specially referred to extreme poverty, and the challenge that it represents to moral education. It treats the problem of poverty in the context of human development, but keeping the poverty as centre of analysis and pedagogical proposals. The article starts from the situation of poverty in 2003, the United Nations Millennium Declaration in 2000, resolved by 189 heads of State or government, in order to eradicate the extreme poverty. It makes an ethical valuation of these situations and sets out the commitments that moral education should assume. It shows the importance of moral practices to transform moral public life, in events referred to poverty, and the education of the student's moral personality. Finally, paying attention to the PNUD Report, 2003, Millennium Development Goals: $a$ compact among nations to end buman poverty, the article exposes five proposals on moral practice with the aim of developing students aptitudes in relation to the eradication of the moral and political blot of poverty. That pedagogical proposals are referred to the sustainable development, the international cooperation, the responsible and just consume, the participation on voluntary services to the society and the political participation.

Key words: poverty, human development, moral education, moral practices, political participation.

\section{SOMMAIRE}

L'article traite de la pauvreté dans le monde, particulièrement de la pauvreté sevère, et le défi qui presente cette situation a l'éducation morale. Actuellement, le problème de la pauvreté est abordé dans le contexte du développement humaine; c'est le même sens de notre article mais en tenant compte de la pauvreté comme centre d'analyse et des propositions pedagogiques. Le point de départ est la situation de la pauvreté à l'année 2003, de la Déclaration du Milennium des Nations Unies de l'année 2000, auxquelles sont arrivés les 189 chefs d'État ou Gouvernement, pour erradiquer la pauvreté sevère. On fait una estimation éthique de telles évenements y on expose les engagements que l'éducation morale devrai assumer devant eux. On expose aussi le rol central des pratiques morales dans le changement morale de la vie publique, dans les affaires qui se rattache a la pauvreté, et la 
formation de la personalité morale des étudiants. Finallement, en tenant compte du PNUD 2003, Les objetifs du developpement bumaine du Millenium: un pacte entre les nations pour erradiquer la pauvreté, se font cinq propositions des pratiques morales pour que les étudiants puissent les adquérir referées à l'érradication du fléau social et politique de la pauvreté. Telles sont les propositions pedagogiques: le développement soutenable, la coopération international, la consommation juste et responsable, la participation dans des mouvements de service volontaire à la société et la participation politique.

Mots clef: pauvreté, développement humaine, éducation morale, pratiques morales, participation politique.

\section{INTRODUCCIÓN}

El papel que se asigna a sí misma la filosofía moral más representativa de nuestro tiempo, la ética discursiva, consiste en aclarar y fundamentar el punto de vista moral ante los problemas que afectan a las personas e instituciones con la pretensión de dar validez universal a las intuiciones morales y refutar así el escepticismo valorativo. Tal papel de la teoría moral tiene una función limitada a señalar y reconstruir el procedimiento de formación de la voluntad común de los afectados por una situación, dejando a cada una de las personas, involucradas en los acontecimientos morales, que encuentre la respuesta a las cuestiones que le salen al paso con la objetividad y urgencia que tienen los acontecimientos históricos.

En vista de las cuatro grandes vergüenzas político-morales que afectan a nuestra propia existencia; en vista del hambre y de la miseria en el Tercer Mundo; en vista de la tortura y la continua violación de la dignidad humana en los aEstados de no-derecho"; en vista del creciente desempleo y de las disparidades en la distribución de la riqueza social en las naciones industrializadas de Occidente; en vista, finalmente, del riesgo de autodestrucción que el armamento atómico representa para la vida en nuestro planeta; en vista de hechos tan provocadores como éstos, la concepción restrictiva que acabo de exponer acerca de lo que puede dar de sí una ética filosófica quizá resulte decepcionante; pero en todo caso también representa un aguijón: la filosofía no releva a nadie de su responsabilidad política (Habermas, 1991, 129-130).

Sin embargo, no se ha tenido siempre tal concepción de la filosofía moral o ética; la tradición griega consideraba la filosofía moral como el conocimiento práctico que permitía orientar las acciones para solucionar los problemas del contexto social o ciudad en la que se vive; en Aristóteles, la filosofía moral tiene como finalidad la acción en un contexto político: "Nadie puede ser justo fuera de su participación en alguna polis particular, nadie tampoco puede ser racional en lo práctico fuera de su participación en alguna polis particular" (Macintyre, 1994, 130). Ambas 
tradiciones de filosofía moral perviven en las corrientes liberales y comunitaristas, tan conocidas y debatidas entre nosotros.

La educación moral actual no puede renunciar a los procedimientos por los que los estudiantes pueden fundamentar un juicio válido de lo que debe hacerse ante los acontecimientos morales que viven, ni puede renunciar al compromiso con la solución de los problemas morales de nuestro tiempo. Por lo tanto, la educación moral tiene un reto doble: el aprendizaje por el estudiante de las competencias (Bernal, 2003) que le permiten analizar y decidir lo que debe ser hecho y el aprendizaje de la participación responsable en la solución justa de los problemas sociales. La meta de la educación es hacer responsable a la gente, enfrentarla a verdaderos problemas, a verdaderas elecciones (Reboul, 1999). Las cuatro grandes vergüenzas político-morales, que nos señala Habermas, tienen que ser grandes objetivos, que imanten los esfuerzos de quienes nos dedicamos a la educación moral, para que los estudiantes salgan de las aulas con capacidades para enfrentarse adecuadamente a ellas.

No creemos que la solución de esos problemas sea una cuestión sólo educativa ni fácil, no tenemos esa ingenuidad; la solución tiene que venir de quienes tienen el poder, personas e instituciones, para solucionar esos asuntos tan complejos. Sin embargo, no podemos esperar que los detentadores del poder se esfuercen en la solución de los problemas si no son impelidos a ello por la presión de ciudadanos y de redes de organizaciones sociales que les retiren el poder político o les combatan políticamente o dejen de comprar los productos de sus empresas, si no lo hacen.

La educación tiene que preparar a los ciudadanos para que sean capaces de esas acciones. La educación consiste en acompañar a los estudiantes para que alcancen la madurez, para que adquieran capacidades de pensar y decidir por sí mismos, de ser responsables de sus propias vidas y de participar activamente en el funcionamiento de sus comunidades.

La educación moral, en concreto, consiste en el diseño de prácticas para que los estudiantes adquieran: las capacidades cognitivas para alcanzar los principios morales sobre lo que debe ser hecho, el significado de ciertos valores que llamamos morales, el juicio práctico para aplicar los principios morales a la complejidad de las situaciones sociomorales, también las disposiciones afectivas para actuar de acuerdo a tales juicios y, fundamentalmente, las capacidades de comportarse en las relaciones con los demás y con la comunidad de acuerdo a lo que han pensado como obligatorio. En los procesos de adquisición de tales competencias consiste la formación de la personalidad moral (Puig, 1996).

Pero tenemos que delimitar el ámbito al que nos referimos cuando hablamos de moral. La caracterización como moral se atribuye a una situación social cuando las personas afectadas por la misma pueden obtener un perjuicio o beneficio de importancia, según se produzcan los acontecimientos en un sentido u otro. Cualquier situación no es necesariamente moral, sólo aquella en la que las personas pueden no recibir lo que les es debido en justicia, de tal manera que se produce 
un grave daño a su dignidad como personas. Igualmente morales no son todos los valores, sino aquellos que son exigibles, cuya ausencia en las relaciones personales y sociales vulnera la dignidad humana. Una persona puede exigir de otra el respeto a su libertad, o la consideración como un igual en cuanto a dignidad personal, o el respeto a las convicciones y costumbres de su cultura (Cortina, Escámez y Pérez Delgado, 1996). Por lo tanto, valores morales son la dignidad humana, la justicia, la libertad, la igualdad, la solidaridad, la tolerancia activa, la honestidad en decir la verdad, el diálogo que busca el entendimiento, el respeto a la naturaleza, la paz y, en determinadas circunstancias, la responsabilidad.

La educación moral, por lo tanto, es el proceso de aprendizaje del estudiante cuando está referido a principios generales, situaciones, valores, disposiciones afectivas y acciones sobre lo que se debe a las personas en las relaciones de unas con otras, a la comunidad política propia, a la comunidad humana y a la naturaleza.

Las situaciones de pobreza severa que viven los ciudadanos del Cuarto Mundo, en los barrios deprimidos de nuestras ciudades, y muchos pueblos del Tercer Mundo son situaciones inmorales, situaciones genuinamente inmorales que tendrían que vigorizar las deliberaciones, los sentimientos y los compromisos responsables de los estudiantes y profesores cuando se diseñan prácticas escolares para educar moralmente. En las situaciones de pobreza severa no están presentes el valor de la libertad, ni la consideración igual de las personas, ni la solidaridad; como se sabe, la pobreza genera frecuentemente situaciones graves de violencia por lo que tampoco tiene presencia el valor de la paz. La dignidad de las personas, en tales situaciones, está gravemente lesionada.

Sin embargo, la pobreza no es punto de reflexión y compromiso moral en la sociedad y en la escuela. Aún más, la pobreza representa aquella situación ante la que todo el mundo apartamos la vista con una cierta repugnancia. En nuestras ciudades, se espera con ilusión la llegada de los miembros de las Casas Reales árabes, mientras que se rechaza a los ciudadanos de sus países cuando vienen buscando trabajo para alimentar a las familias. Más que xenofobia, tenemos aporofobia, que ha sido descrita (Martínez, 2002) como un sentimiento difuso de rechazo al pobre, al desamparado, al que carece de salidas, al que carece de medios y recursos. No marginamos al inmigrante si es rico, ni al negro que es jugador de baloncesto con notables ingresos, ni al jubilado con patrimonio; a quienes marginamos es a los pobres. Lo más grave del asunto es que hemos aprendido el mecanismo psicológico de hacerles responsables de su situación: "no les gusta trabajar", "no se cualifican profesionalmente", "son indisciplinados"; en definitiva, se les considera culpables de la miseria que les aqueja.

En el presente artículo tratamos la pobreza, especialmente la pobreza severa, y el reto que presenta a la educación moral. Sabemos que los especialistas plantean la pobreza en el contexto del desarrollo humano. Nosotros también lo haremos, pero teniéndola como centro de atención. En torno a la pobreza de las personas y de los pueblos, dos reflexiones más que nos ayudan a comprender la poca atención que se le ha prestado en nuestro tiempo. La primera la podemos formular así: en 
sociedades como las nuestras, organizadas en torno a la idea de contrato en cualquiera de las esferas sociales, el pobre, el verdaderamente diferente en cada una de ellas, es el que no tiene nada que ofrecer a cambio y, por lo tanto, no tiene capacidad real de contratar; los pobres son los excluidos del intercambio, no tienen un lugar en nuestras sociedades desarrolladas. La segunda reflexión nos la da Suárez del Toro, presidente de Cruz Roja Española y de la Federación Internacional de Sociedades de Cruz Roja Internacional y de la Media Luna Roja:

\begin{abstract}
Un tema que me preocupa es la politización de la ayuda internacional. Y ése es un tema nuevo. En otro tiempo había menos ayuda, pero en cualquier caso, la que hoy tenemos no es suficiente, y además cada vez está más politizada. Hasta el extremo de que nosotros mismos nos planteamos qué podemos hacer para evitar caer en esa trampa, en la que a veces caemos, y que nos conduce a prestar atención a los temas que van a tener más éxito o conseguir más eco; en lugar de hacer una elección según las necesidades reales. Hay pobreza, enfermedades, falta de educación. Tragedias que afectan a miles de millones de personas, y el caso es que pasamos ante ellos sin mirarlos (Suárez del Toro, 2003).
\end{abstract}

\title{
2. LA SITUACIÓN DE POBREZA EN EL AÑO 2003
}

El Informe sobre Desarrollo Humano (PNUD, 2003) está dedicado a la descripción de los principales problemas de la pobreza en el mundo, al análisis de sus causas y a la presentación de propuestas concretas para acelerar la erradicación de la pobreza extrema. El informe parte de la Declaración del Milenio de las Naciones Unidas del año 2000, adoptada por 189 líderes políticos, la mayor concentración de jefes de Estado y de Gobierno de la historia. Estos dirigentes prometieron unir esfuerzos para lograr que, en el año 2015 o antes, se cumpliesen unos objetivos concretos de avance en el desarrollo y reducción de la pobreza. Estos objetivos, así como los compromisos para cumplirlos que adquirieron los países ricos y pobres, fueron ratificados en el Consenso de Monterrey, surgido a raíz de la Conferencia de las Naciones Unidas sobre la Financiación para el Desarrollo de marzo de 2002, en la Cumbre Mundial de Desarrollo Sostenible, en Johannesburgo 2002, y en el lanzamiento de la Ronda de Doha, Qatar 2001, sobre Comercio Internacional.

El acuerdo alcanzado entre los países es la base del Pacto de Desarrollo del Milenio (PNUD, 2003, 1-3), presentado como una propuesta política para alcanzar los siguientes ocho objetivos: erradicar la pobreza extrema y el hambre; lograr la educación primaria universal; promover la equidad de género y la autonomía de la mujer; reducir la mortalidad infantil; mejorar la salud materna; combatir el viH/sIDA, el paludismo y otras enfermedades; garantizar la sostenibilidad ambiental y fomentar una asociación mundial para el desarrollo. Para el cumplimiento de esos objetivos, se establecen diecisiete metas a conseguir en fechas concretas desde 2005 a 2020. 


\subsection{Datos sobre los indicadores de la pobreza ${ }^{1}$}

A continuación se describen algunos datos significativos en relación con diversos indicadores de la pobreza: ingresos de renta, hambre, educación, salud, acceso a infraestructuras de agua potable y saneamiento; también se atiende a las desigualdades según género (PNUD, 2003).

Más de 1.200 millones de personas, una de cada cinco de todo el mundo, sobrevive con menos de 1 dólar al día. Durante los años 90 , la proporción de personas que sufría esa pobreza de ingresos descendió de un $30 \%$ a un $23 \%$. Sin embargo, teniendo en cuenta el crecimiento de la población mundial, la cifra sólo descendió en 123 millones. Si se excluye a China, la cifra de personas que viven con menos de 1 dólar aumentó en 28 millones.

Cada día, en los países en desarrollo, 799 millones de personas pasan hambre (aproximadamente el $18 \%$ de la población mundial). India es el país que registra mayor número de personas afectadas por el hambre con 233 millones, seguida del África Subsahariana con 183 millones, China con 119 millones, el resto del Asia Oriental y el Pacífico con 74 millones, América Latina con 55 millones y los Estados Árabes con 32 millones. A nivel mundial, el número de personas que pasan hambre se redujo en 20 millones entre 1991 y 1999, pero este avance se debe exclusivamente a que 80 millones de chinos escaparon de la pobreza. En 25 países en desarrollo se produjo un aumento del número de personas que pasan hambre.

En los países en desarrollo, de los 680 millones de niños en edad de escolarización primaria, 115 millones no asisten a la escuela, tres quintas partes de los cuales son niñas. Por otra parte, la matriculación escolar y finalización de etapa no son sinónimos: poco más de la mitad de los niños que inician la etapa de enseñanza primaria la concluyen; y, en el África Subsahariana, la proporción es uno de cada tres. A causa de estas deficiencias, la cuarta parte de los adultos de los países en vías de desarrollo no saben leer y escribir, siendo mujeres las dos terceras partes de los 879 millones de adultos analfabetos que hay en el mundo.

1. Así como el Índice de Desarrollo Humano (IDH) mide el progreso general de un país en la consecución del desarrollo humano, el Índice de Pobreza Humana (IPH) mide los atrasos en las privaciones que todavía existen. Se manejan dos índices de pobreza humana: el referido a los países en desarrollo IPH-1 y el referido a los países de la OCDE, IPH-2. El IPH-1 atiende los siguientes indicadores: longevidad, medida con la probabilidad, al nacer, de no vivir hasta los 40 años; conocimientos basándose en la tasa de alfabetización de adultos; y suministro económico general, público y privado, medido según el porcentaje de personas que no utilizan fuentes de agua mejoradas, el porcentaje de los que carecen de acceso sostenible a fuentes de agua mejorada y el porcentaje de niños de peso inferior al normal. El IPH-2 mide las privaciones en los mismos aspectos que el IPH-1 y en uno más: la exclusión social. Se basa en los siguientes indicadores: la probabilidad, al nacer, de no vivir hasta los 60 años; la tasa de adultos que carecen de aptitudes de alfabetización funcional; el porcentaje de personas que viven por debajo del umbral de la pobreza de ingresos (ingresos disponibles ajustados por hogar inferiores al 50\% de la media de renta neta; y la tasa de desempleo de larga duración (12 meses o más). El índice relativo al género mide las privaciones en las mismas dimensiones, según la diferencia de género. (Fuente: Oficina de Desarrollo Humano). 
Cada día mueren en el mundo más de 30.000 niños por causas que se podrían prevenir (deshidratación, hambre, enfermedades evitables). Cada año, más de 500.000 mujeres mueren como consecuencia del embarazo y del parto. En el África Subsahariana, una mujer embarazada tiene 100 veces más posibilidades de morir durante el embarazo y el parto que en un país de altos ingresos de la OCDE. La tuberculosis es otra de las causas de la mortalidad adulta: hasta 2 millones de personas mueren al año por esa enfermedad. La muerte por paludismo asciende a 1 millón de personas al año.

En el año 2000, al menos 1.100 millones de personas, uno de cada cinco habitantes del mundo, carecía de acceso al agua potable y alrededor del doble, 2.400 millones de personas, carecían de acceso a saneamiento mejorado. En Asia vive el $65 \%$ de la población sin acceso al agua potable y en África el 28\%. En los años 90, el número de niños muertos por diarrea, causada por la falta de agua y saneamiento seguros, superó a las víctimas de conflictos armados registradas desde la Segunda Guerra Mundial. La mitad de las camas hospitalarias del mundo están ocupadas por pacientes con enfermedades transmitidas por el agua.

En los países en vías de desarrollo, un claro indicador de la crisis de género es el distanciamiento de mortalidad entre hombres y mujeres. A pesar de la ventaja biológica de las mujeres, éstas tienen tasa de mortalidad más alta en varios países, principalmente en Asia Meridional y Oriental. La brecha entre géneros en la salud y, particularmente, en la educación son una manifestación de la discriminación. Tal y como expone el informe PNUD 2003, la igualdad entre los géneros es un elemento esencial para determinar si se alcanzarán o no los objetivos de la Declaración del Milenio: desde la mejora de la salud y la lucha contra la enfermedad, a la reducción de la pobreza y el hambre; desde la difusión de la educación y la disminución de la mortalidad infantil, al aumento del acceso al agua potable.

Los datos que se han proporcionado en los párrafos anteriores, son las medias estadísticas de diferentes indicadores de pobreza de los llamados países en vías de desarrollo, pero no todos los países, ni toda la población dentro de un mismo país, están en la misma situación. En cada país hay brechas entre grupos socioeconómicos, ciudades y campo, mayorías y minorías étnicas, etc.; siendo los beneficiarios de los escasos recursos la población con mayores ingresos económicos, los habitantes de las ciudades y las personas que pertenecen a las mayorías étnicas.

Aunque el Índice de Pobreza Humana se mide con distintos indicadores según se aplique a los países en vías de desarrollo (IPH-1) o a los países desarrollados (IPH2), siendo las características de la pobreza de unos países y otros muy diferentes, por lo que no se pueden homologar, la lacra política y moral de la pobreza aparece también en los países desarrollados:

Pese a esta evolución positiva (del crecimiento europeo en la década de los noventa y la mejora de la situación del empleo), el nivel del desempleo sigue siendo demasiado elevado. En consecuencia una parte considerable de la población de la UE sigue bajo la amenaza de la pobreza y de la exclusión social, 
situación que podría empeorar dadas las recientes dificultades experimentadas por la economía europea (Eurostat, 2002, 11).

El indudable crecimiento económico de la uE se distribuye desigualmente entre los diversos sectores de la población de los diferentes países que la conforman. A nivel comunitario, el $20 \%$ más pobre de la población percibió el $8 \%$ de la renta total en 1998 , mientras que el $20 \%$ más rico obtuvo el $39 \%$, es decir, 5,4 veces más. Esta ratio es generalmente más elevada en los Estados miembros situados al sur y no continentales: Portugal ocupa la no meritoria posición de número 1 con un 7,2, pero Bélgica, Irlanda, España, Grecia, Italia y el Reino Unido forman parte del grupo que ocupa la zona superior a la media europea; en la zona por debajo de la media se encuentran Dinamarca, Suecia y Austria. En general, los países en que las desigualdades de renta son mayores tienen un ingreso medio menor por habitante, a excepción del Reino Unido (Eurostat, 2002).

Es conveniente distinguir entre pobreza relativa o precariedad económica (ingresos disponibles por hogares inferior al 50\% de la media de renta neta) y la pobreza severa (quienes no gozan de los beneficios de los sistemas de protección que garantizan los mínimos ingresos para cubrir las necesidades básicas). Debido a los sistemas de protección social de los diferentes países de la UE, se calcula que viven en la pobreza extrema entre el 2,5 y el $3 \%$ de la población europea, con diferencias en los porcentajes según países. Estos datos nos indican que hay una porción significativa de la población a la que no alcanza el crecimiento económico, ni la distribución de la protección social básica; tal población conforma un núcleo resistente de pobreza severa que exige otras políticas más eficaces que las aplicadas. Es la pobreza, muchas veces invisible, que está junto a nosotros.

\section{Una mirada moral sobre la pobreza y sobre la DeClaración del Milenio}

Como podemos observar en los datos aportados por los diferentes descriptores, una parte importante de la población mundial malvive y muere de pobreza extrema. Las situaciones que la pobreza manifiesta son radicalmente inmorales, injustas, por lo que su solución no es una cuestión de caridad sino de justicia: la satisfacción de las necesidades básicas que garanticen una vida de mínimos, pero digna. El reconocimiento de estas realidades debiera ser el punto de partida de la discusión social, la planificación política, la reflexión y la educación moral. El desconocimiento y ocultamiento de la realidad de la pobreza, y de las injusticias que la provocan, corta de raíz la posibilidad de la crítica y del cambio de las situaciones políticas y sociales en las que se muestra (Cardenal, 1999). La educación, si se pretende moral, no puede refugiarse en situaciones o problemas artificiales e imaginarios. Si la pobreza y las víctimas son tan normales en nuestro mundo, se puede cuestionar la desmesurada ambición de la riqueza que provoca esas situaciones; también se puede denunciar la exhibición del consumismo que se hace en el Primer Mundo, hasta ser considerado motor de desarrollo económico y motivo de 
prestigio social de las personas y las familias. La educación moral tiene en la pobreza un ámbito temático sustancial y significativo, centro de las preocupaciones de muchas gentes y de los dirigentes de la sociedad civil y de la política cuando son decentes y responsables.

La reflexión atenta sobre la pobreza permite entender las migraciones de nuestro tiempo y sus consecuencias asociadas. La respuesta natural de la población excluida de los bienes básicos, que garantizan la vida, es moverse hacia aquellos lugares donde espera encontrar oportunidades mejores para vivir. Esto explica la migración del campo a la ciudad y de los países del sur al norte. Nos escandalizamos de las tragedias que suceden en nuestras costas cuando mueren ahogados niños, mujeres y hombres al caer de las pateras; cuesta comprender que puedan jugarse la vida para alcanzar la costa de un país que sólo le ofrece un futuro incierto $\mathrm{y}$, con total seguridad, muy difícil; sin embargo, los desheredados y excluidos, los verdaderamente pobres, aceptan el riesgo porque es la oportunidad que les queda de sobrevivir. Los que vienen aquí, jugándose la vida, no hacen turismo. Lo hacen por la necesidad generada desde una injusta distribución de la riqueza:

No se puede dejar a los tres cuartos de la humanidad en la miseria mientras nosotros vivimos en la opulencia. Un dólar por día para más de 1.000 millones de seres humanos no es una cifra, es una vergüenza. Un insulto a la dignidad del hombre. Es ilusorio pensar que esta solidaridad humana se compensa mandando dinero o sólo apoyando a organizaciones caritativas (aunque esto sea de todas maneras necesario). La solidaridad es necesaria aquí mismo. Tiene que manifestarse con la actitud con los nacionales de estos países: ¿Qué hacemos para facilitar la integración de los inmigrantes, para luchar contra el racismo y la xenofobia, para que dispongan de los mismos derechos y acepten los mismos deberes que nosotros? ¿Qué hacemos para dar a entender a la opinión pública que los que piden trabajo, ayuda, cuestionan en el fondo nuestras relaciones globales con ellos? La respuesta no se puede reducir a patrullas policiales en las fronteras (Sami Naï, 2003).

La pobreza de ingresos está inevitablemente unida a la falta de capacidades; no son lo mismo pero, como se ha observado en los datos de los indicadores, la pobreza de ingresos va unida a graves deficiencias en la educación y la salud. Así se produce un círculo infernal: la pobreza de renta va asociada a educación y salud precarias que, a su vez, impiden la adquisición de las capacidades por esas personas para ganar una renta y librarse, asimismo, de la pobreza de renta (Sen, 2000). Cuanto mayor sea la cobertura de la educación básica y de la asistencia sanitaria, más probable es que las personas pobres tengan oportunidades de vencer a la miseria. La mejora de las capacidades humanas tiende a ir acompañada de un aumento de las productividades y del poder para obtener ingresos. Una consecuencia fundamental de la consideración de la pobreza, como privación de capacidades, es una nueva mirada sobre el pobre: es víctima, no culpable; se le ha negado la posibilidad de adquirir las capacidades para salir de su situación, a veces por quienes le culpan. Por ello, la mirada moral sobre la pobreza conduce a con- 
siderarla como un problema de justicia: entregar a los excluidos de las riquezas de la tierra aquello que les pertenece.

Respecto a la pobreza del Cuarto Mundo, las bolsas de pobreza de los países desarrollados, también produce una reducción en el desarrollo de las capacidades humanas. Una de las causas fundamentales de tal situación es producida por el paro. El informe de Eurostat de la Comisión Europea, 2002, situaba en el 4,5\% a los ciudadanos europeos que viven en hogares en los que ningún miembro tiene un trabajo remunerado. Tal hecho, merece también una consideración moral. Existen abundantes pruebas de que el paro produce otras consecuencias perversas, además de la pérdida de renta; entre ellas, se encuentran los daños psicológicos, la pérdida de motivación para trabajar, de cualificación profesional y de confianza en uno mismo, el aumento de las enfermedades, la perturbación de las relaciones familiares, el aumento de la exclusión social y de las asimetrías entre sexos (Sen, 2000).

La ayuda internacional, ante una emergencia producida por la guerra o por una catástrofe de la naturaleza, está muy bien, pero compromete a poco. Lo verdaderamente difícil es cooperar constantemente con un volumen de ayuda suficiente para solucionar la pobreza extrema o al menos mitigarla sustancialmente; y la cooperación es un asunto de justicia, como venimos sosteniendo. Lo importante de la Declaración del Milenio está en la formulación concreta de objetivos y metas cuantificables en su logro; también en los compromisos adquiridos por los dirigentes de los países pobres y ricos para alcanzarlos; de esos compromisos se pueden pedir cuentas políticas, también morales, puesto que se ha hecho un pacto internacional que obliga a su cumplimiento.

Los compromisos adquiridos por los países ricos se detallan en el "Objetivo 8: Fomentar una asociación mundial para el desarrollom. Digamos de nuevo que tales compromisos han sido reafirmados en el Consenso de Monterrey, 2002, en el que se insta a los países donantes a alcanzar el objetivo del 0,7 del PNB para ayuda internacional a los países en vías de desarrollo; en la reunión de la Organización Mundial del Comercio celebrada en Doha, Qatar, en 2001, se reafirmaron los objetivos de reducción de la pobreza y se prometió conseguir un acceso al mercado, sin aranceles y cupos, para los productos procedentes de los países más pobres; la Cumbre Mundial sobre Desarrollo Sostenible, celebrada en Johannesburgo, en 2002, reiteró la necesidad de alcanzar el 0,7 y reducir la deuda no sostenible de los países que demuestren gobernabilidad (gobiernos que traten de conseguir niveles de convivencia democrática y equitativa). Aunque la ayuda oficial para el desarrollo ha ido disminuyendo, entre 1990 y 2001, del 0,33\% al 21\% de los ingresos nacionales brutos de los países donantes, los datos más recientes muestran que la tendencia se ha invertido con un aumento del 5\% entre 2001 y 2002.

El cumplimiento de los acuerdos para dedicar el 0,7 a la ayuda internacional, a los países en vías de desarrollo, es de gran importancia: si los miembros del Comité de Asistencia para el Desarrollo de la OCDE (los 23 países donantes más grandes del mundo) proporcionaran realmente una asistencia oficial para el desarrollo igual al 0,7 de su PNB, la ayuda ascendería a 165 millones anuales de dólares, 
tres veces el nivel actual y muy por encima de los cálculos actuales sobre lo que se necesita para alcanzar los objetivos del Desarrollo del Milenio ${ }^{2}$.

Los valores que rigen la Declaración del Milenio y los objetivos de Desarrollo del Milenio son morales, por lo que la defensa y la presión para su cumplimiento se convierte en un asunto moral. Entre tales valores, se hace una referencia especial a la libertad, la igualdad, la solidaridad, la tolerancia, la responsabilidad en común y el respeto a la naturaleza "como esenciales para las relaciones internacionales en el siglo XXIm (PNUD, 2003: 28).

\section{La sospecha de incumplimiento del PaCto del Milenio sobre la pobreza y LA FUNCIÓN DE LA EDUCACIÓN MORAL}

Ante este tipo de pactos y declaraciones internacionales, como también sucede con los derechos humanos, suele haber entre los ciudadanos un cierto escepticismo: está muy bien que los representantes de los Estados donantes prometan que aportarán determinadas ayudas para combatir la pobreza y que los representantes de los Estados de los países en vías de desarrollo prometan que harán reformas políticas atendiendo a la gobernabilidad (democracia y equidad en la convivencia) pero, si no se ha atribuido a dichos Estados alguna obligación estricta de la que dar cuenta ante un tribunal internacional, ¿quién garantiza que cumplirán las promesas? Es lo que se ha denominado la "crítica de la coherencia" (Sen, 2000). De este problema se hace cargo Richard Jolly cuando dice: "Es frecuente que se rechacen los objetivos de las Naciones Unidas, ya que se les acusa de ser demasiado ambiciosos y de que apenas llegan a lograrse" (PNUD, 2003: 31) para, a continuación, hacer un listado de aquellos objetivos que sí se han logrado como la erradicación de la viruela y la polio, la reducción de la mortalidad infantil y otros muchos.

Sin embargo, la sospecha de la falta de cumplimiento de las promesas internacionales no carece de cierto fundamento. En relación con los países en vías de desarrollo, que tienen que hacer las reformas políticas que aseguren la gobernabilidad, puesto que son los agentes principales en la consecución de los 7 primeros

2. Promesas desde Monterrey: En la conferencia internacional sobre Financiación para el Desarrollo, celebrada en 2002 en Monterrey (México), la comunidad internacional acordó un aumento de la ayuda, por primera vez en 20 años, con 16.000 millones de dólares adicionales para el año 2006. Los Estados Unidos casi duplicarán la ayuda oficial para el desarrollo, hasta 15.000 millones al año, para 2006. La Unión Europea aumentará la ayuda hasta el 0,39 para el 2006, hasta 11.000 millones de dólares. Entre los Estados miembros de la UE, éstos son los compromisos: Alemania, el 0,33 (2006); Austria, el 0,33 (2006); Bélgica, el 0,7 (2010); España, el 0,33 (2006); Finlandia, el 0,4 (2007); Francia, el 0,5 (2007); Grecia, el 0,33 (2006); Irlanda, el 0,7 (2007); Italia, el 0,33 (2006); Luxemburgo, el 1,0\% (2005); Los Países Bajos, el 1\% (2005); Portugal, el 0,33 (2006); Reino Unido, el 0,4 (2005-06); Suecia, el 1\% (2006). Otros países también hicieron importantes promesas: Canadá, el 0,28 (2010); Noruega, el 1\% (2005); Suiza, el 0,37 (2010); Australia, el 3\% (2002-03). (Fuente: Naciones Unidas, 2002a; Reino Unido, Her Majesty's Treasury, 2003; OCDE, Comité de Asistencia para el Desarrollo, 2003d). 
objetivos del pacto contra la pobreza, el Informe sobre Desarrollo Humano 2002 (PNUD, 2002) nos dice que de los 147 países que hay datos, 121, con el $68 \%$ de la población mundial, tenían en el año 2000 todos o varios de los elementos propios de las democracias formales; en el año 1980 eran sólo 54 países, con el 46\% de la población mundial. Desde entonces, 81 países han avanzado hacia la democracia, mientras que 6 han sufrido retroceso. Claramente desde 1980 se aprecia una mejora de las libertades políticas; pero las transiciones a la democracia siempre son problemáticas, con avances y retrocesos. Es, precisamente, en muchos de los países de pobreza extrema, donde se aprecia un leve retroceso democrático como en el África Subsahariana y el Asia Meridional. También reconoce el Informe que, de los 81 países que han tomado medidas democráticas, sólo 47 se consideran democracias plenas.

Por otra parte, la reunión de la Organización Mundial del Comercio de 2003, en Cancún, según el premio Nobel de Economía de 2002, Joseph E. Stiglitz, puso de manifiesto que Estados Unidos y Europa faltaron a su promesa de que iba a ser una ronda de negociaciones destinada a mejorar las condiciones de pobreza de los países en vías de desarrollo. Es más, no lograron restablecer los desequilibrios comerciales producidos en las rondas de negociaciones anteriores. Estados Unidos y Europa no sólo intentaron imponer sus prioridades comerciales a los países en vías de desarrollo, sino que siguieron insistiendo en mantener los subsidios agrarios a sus agricultores y plantearon nuevas exigencias que perjudicaban a los países en vías de desarrollo. Por primera vez, los países en vías de desarrollo se unieron y las negociaciones fracasaron (Stiglitz, 2004).

Como puede observarse, aunque los gobernantes de unos Estados intenten dar explicaciones de sus incumplimientos culpando a los gobernantes de otros Estados, el hecho es que la puesta en práctica de las promesas pactadas ofrece graves dificultades. Conscientes de esas dificultades, los redactores del Informe PNUD, 2003, hacen un llamamiento a la implicación de la sociedad civil, desde organizaciones comunitarias hasta asociaciones profesionales, agrupaciones de mujeres y redes de organizaciones no gubernamentales (ONG), para que obliguen a los gobiernos a mantener la voluntad política de cumplir sus promesas:

Uno de los avances más significativos registrados en la última década ha sido la creciente influencia de las redes y organizaciones de la sociedad civil - tanto locales como nacionales y mundiales- en los cambios políticos y en el alivio de la deuda. Se convoca con regularidad a las organizaciones no gubernamentales (ONG), las organizaciones comunitarias, las asociaciones de profesionales, y otros grupos de la sociedad civil para que participen en el diseño y en la implementación de estrategias de reducción de la pobreza (PNUD, 2003, 23-24).

La importancia que se concede a la movilización del apoyo popular por los redactores del Informe se muestra con la dedicación de todo el capítulo 7 a este tema. Se considera que la realización de las políticas e intervenciones necesarias para alcanzar los objetivos de Desarrollo del Milenio exige la convicción de los 
líderes políticos pero también una presión política sostenida, un amplio apoyo popular. Para dicha movilización popular y compromiso cívico participativo resulta esencial un Estado democrático abierto que garantice las libertades políticas y civiles, de modo que los pobres puedan presionar a sus líderes para que éstos cumplan sus compromisos con respecto a los objetivos. El referenciado capítulo 7 hace un análisis detallado de varios países en vías de desarrollo, mostrando los beneficios de la participación popular y de la descentralización para la reducción de la pobreza en varios de sus indicadores; y dedica una mención especial al experimento participativo y de descentralización llevado a cabo en Porto Alegre (Brasil), que tan buenos resultados ha dado.

La participación y movilización cívica también tiene que producirse en la ciudadanía de los países donantes. Debe realizarse una vigilancia y seguimiento sobre el volumen y la calidad de ayuda para garantizar que son coherentes con el logro de los objetivos de la reducción de la pobreza.

El Pacto de Desarrollo del Milenio ofrece un marco en el que los países menos avanzados desarrollen y asuman la responsabilidad de sus propios planes nacionales, basados en una asistencia externa sostenida, para escapar de las trampas de la pobreza y mejorar el bienestar de los ciudadanos más pobres. El punto más importante del Pacto, que debe guiar las políticas de los países ricos y pobres, es el siguiente: si un país adopta las medidas políticas adecuadas y se compromete a realizar una buena gestión pública en la aplicación de dichas medidas políticas, la comunidad mundial (organismos internacionales, países donantes, actores privados y organizaciones de la sociedad civil) debe ayudar a dicho país a alcanzar los umbrales mínimos de satisfacción de sus necesidades, incrementando su ayuda.

El papel que compete a los ciudadanos, tanto de los países en vías de desarrollo como de los países desarrollados, consiste fundamentalmente en la participación en la vida pública para que los dirigentes, de unos y otros Estados, cumplan con su parte del Pacto contra la pobreza. La participación en la vida pública es el ámbito privilegiado de la vida moral o, dicho de otra manera, la participación en la vida pública es un ingrediente indispensable de la vida moral (MacIntyre, 1987; Escámez, 2003). La educación moral tiene que recuperar la orientación que siempre tuvo en las grandes tradiciones educativas: la formación de los estudiantes para que ejerzan como ciudadanos competentes, analizando y actuando para la solución de los problemas que afectan a su comunidad política y a la comunidad humana (Cortina, Escámez y Pérez-Delgado, 1996).

Creemos que se ha empleado mucho tiempo en discusiones académicas, academicistas a veces, sobre las virtualidades del liberalismo o comunitarismo como teorías éticas sobre las que fundamentar la educación moral; y quizás haya sido conveniente. Pero, hay que volver a la cuestión que interesa a los grandes autores sobre educación moral: cómo formar a los ciudadanos para que participen en la vida pública de acuerdo a criterios de justicia. Es comúnmente aceptada entre los especialistas, la función política que la tradición comunitarista, con raíces aristotélicas, atribuye a la educación moral (Naval, 1995); la función política de la educa- 
ción moral en los planteamientos de autores de la tradición liberal, que sí se discute, creemos que también la aclara el siguiente texto:

La escuela pública está obligada al mantenimiento de la justicia como lo están los tribunales. El actuar contra las leyes de segregación racial en las escuelas es no solamente un reconocimiento de los iguales derechos de los ciudadanos para acceder con la misma facilidad a la escuela pública, sino un activo reconocimiento de la responsabilidad de la escuela en la educación moral, esto es, de la responsabilidad en la transmisión de los valores de justicia sobre los que nuestra sociedad está fundamentada. Desde mi punto de vista, por tanto, la educación moral puede legítimamente implicar ciertos elementos de reforma social si se refiere directamente a los valores centrales de justicia sobre los que las escuelas están basadas (Kohlberg, 1981, 38) ${ }^{3}$.

La pobreza es un hecho social que afecta a las personas: unas veces privando del derecho a la vida, otras veces produciendo enfermedades evitables, siempre obstaculizando el desarrollo de las capacidades humanas; por lo que la situación de pobreza extrema vulnera la dignidad de las personas. La lucha contra la pobreza es un proyecto moral, a la vez que político, de primer orden; de la supresión o minimización de la misma depende la solución o mitigación de muchos de los problemas que afectan a las sociedades de nuestro tiempo como ciertas situaciones de violencia, las migraciones masivas y las guerras. ¿Cómo puede la escuela, y las otras agencias educativas, participar en tal proyecto moral? Ésa es la cuestión que tiene que enfrentar la educación moral.

\section{5. ¿CÓMO EDUCAR MORALMENTE ANTE LA POBREzA?}

Los dos problemas, que siempre preocupan a quienes nos dedicamos a la educación moral son: el primero, cómo organizar los procesos de aprendizaje de los estudiantes en conocimientos, en sentimientos y en capacidades de acción para que se comporten como sujetos morales; y, el segundo de los problemas, si los aprendizajes se producen cuando los contextos escolares o los contextos familiares o el barrio o los medios de comunicación o el uso de Internet muestran un clima de inmoralidad o un clima ajeno a los valores morales. José María Puig formula muy bien una tesis que compartimos:

Parece que los sujetos están tan inmersos en sus medios socioculturales que poco se puede hacer para educarlos sin convertir tales medios en objeto de estudio, en espacios de intervención y quizás en lo que debe transformar la educación. En la medida que el medio está tan pegado al sujeto que en cierto modo es ya sujeto, cabe educar al medio para educar el sujeto. La educación moral es construcción de

3. La traducción es de uno de los autores del artículo. 
la personalidad y construcción del medio en el que se forma la personalidad (Puig, 2003, 46).

Nos invita el profesor Puig a imaginarnos al sujeto inmerso en el medio como un agente constituido socioculturalmente, sin por ello quedar borrado en tanto que sede de operaciones que le son propias; un agente reflexivo, no omnipotente, pero capaz de convertirse en una fuerza significativa para el cambio social; y un agente educable, pero no únicamente interviniendo directamente sobre él mismo, sino construyendo un medio que se convertirá en parte integrante del mismo sujeto. Nos invita a una imagen de la persona que conforma su identidad personal a partir de su medio sociocultural, pero con capacidad para una cierta elaboración personal o reconstrucción de las influencias recibidas que, a su vez, se refleja transformando, en cierta medida, el medio social y cultural. Tal imagen de las relaciones del sujeto y el medio responde, a lo que consideramos, una visión antropológica adecuada.

El acierto de J. M. Puig, en nuestra opinión, está en focalizar la relación del sujeto y su medio en "las prácticas sociales": son el escenario en el que se refleja la influencia de las estructuras sociales en las acciones de los sujetos y, a su vez, la modificación de esas estructuras sociales por influencia de las acciones de los mismos sujetos. Aunque va exponiendo el concepto de práctica social en varios autores, fundamentalmente en A. Giddens (1995a, 1995b) y en MacIntyre (1987, 1992, 1994), su concepción personal se puede resumir así: los sujetos no tienen un protagonismo absoluto en las prácticas sociales que llevan a cabo; no gozan de una libertad ilimitada sino que sus prácticas están en cierto modo pautadas por la influencia social; pero tampoco pierden su calidad de agentes intencionales que se comportan de acuerdo a proyectos personales. Las prácticas sociales son productos culturales de la comunidad y, a la vez, son realizaciones personales de los sujetos participantes en ellas; son un espacio donde la acción expresa las constricciones sociales, pero donde esa misma acción reproduce modificadas tales constricciones o condicionamientos sociales.

De ahí, el interés por construir unas condiciones institucionales y unas prácticas sociales que ayuden a llevar conductas morales. La moral es una responsabilidad de los sujetos, puesto que aquello que debe ser hecho remite a su conciencia, en última instancia, pero es una responsabilidad que, en gran medida, se aprende y se ejerce creando las condiciones sociales que invitan al juicio, al sentimiento y a la conducta moral.

Las prácticas morales son un tipo de prácticas sociales cuando en ellas se manifiestan uno o varios de los valores morales, bien en las relaciones de los sujetos entre sí o bien en las relaciones con la comunidad política o con la naturaleza. Si se debaten o deliberan cuestiones o problemas relativos al perjuicio que la pobreza causa a la dignidad humana, si se delibera sobre el modo de orientar las acciones personales o grupales para combatir la pobreza de los países en vías de desarrollo o las bolsas de pobreza de los países desarrollados, si se participa en la 
creación o desarrollo de agencias de cooperación internacional, si se participa en redes sociales para presionar a los gobiernos a cumplir las promesas de alcanzar el 0,7 en ayuda internacional, si se discuten públicamente las políticas gubernamentales en torno a la equidad en la salud y en la educación de los ciudadanos, si se combaten los intentos del poder político de recortar las libertades civiles y políticas como atentados a la dignidad personal de los individuos, etcétera, entonces esas prácticas sociales, caracterizadas como morales ya que encarnan valores morales, están produciendo la educación moral de las personas que participan en ellas, a la vez que la moralización de las instituciones sociales y de la vida pública:

Una práctica efectúa, realiza o actualiza los bienes o valores que le son inherentes. Una práctica es una acción moralmente informada, de ahí que las prácticas no sean un medio para producir el bien o los valores a los que se aspira, sino el lugar mismo donde se encarnan y viven los valores... Cuando proyectamos la realización de asambleas de clase queremos alcanzar los objetivos que antes hemos citado (dar información, organizar y evaluar el trabajo escolar, regular la convivencia y gestionar las actividades recreativas), pero además pretendemos expresar a cada paso valores como la participación, la responsabilidad o el diálogo. Cuando organizamos la clase en pequeños grupos impulsamos la vivencia constante de valores como el compañerismo, la ayuda mutua o la cooperación (Puig, 2003, 142).

Actualmente vivimos la contradicción de una Declaración del Milenio, consensuada por 189 jefes de Gobierno o de Estado, que da lugar a un Pacto Internacional contra la pobreza, y la práctica política de unas relaciones económicas entre países que genera más desigualdades y rechazo a los ciudadanos de los países en vías de desarrollo. El fracaso de las conversaciones de la Organización Mundial de Comercio en Cancún (México, 2003) y los dispositivos policiales en Estados Unidos y la Unión Europea para impermeabilizar las fronteras a los inmigrantes, manifiestan el egoísmo de los países desarrollados, a pesar de que la Declaración pide solidaridad con los débiles y excluidos, porque es lo que legitima verbalmente a las instituciones del mundo occidental, a pesar de que se hacen lenguas de la defensa de los derechos humanos y se organizan cumbres y pactos contra la pobreza.

A pesar de nuestras sospechas de incumplimiento de los pactos internacionales contra la pobreza, hay buenas razones para la existencia de prácticas sociales con cualidades morales, tal como ha sido puesto de relieve a través del concepto de capital social (Herreros y De Francisco, 2001). Abrigamos la esperanza de un sueño europeo comprometido con el cumplimiento de esos pactos internacionales; si se realiza, la Unión Europea habrá conseguido un notable capital social.

Algunos autores, en lugar de criticar a las instituciones políticas, económicas y sociales de determinados países, entienden que es más aconsejable estudiar las causas por las que en determinados lugares la democracia funciona mejor que en otros. La conclusión a la que llegan es que la calidad de los gobiernos representativos está determinada por la presencia de tradiciones prolongadas de compromiso cívico: existe una relación entre el rendimiento, aún económico, de las institucio- 
nes sociales y la densidad de la sociedad civil, entre el funcionamiento de los gobiernos democráticos y la capacidad asociativa de la sociedad civil.

En esa línea de pensamiento, se distinguen tres formas de capital que facilitan la actividad productiva: el capital físico, formado por terrenos, edificios, maquinaria e infraestructuras; el capital humano, las técnicas y los conocimientos que tiene una empresa o institución, se crea mediante cambios en las habilidades y capacidades de las personas que permiten innovaciones productivas; y el capital social constituido por cambios en las relaciones interpersonales, que facilitan la acción en común. Hay tres modalidades fundamentales de capital social: la primera consiste en las obligaciones o pautas impositivas de las estructuras de una sociedad a sus miembros, que generan expectativas en el comportamiento de los mismos y fiabilidad de alcanzar determinados logros si se actúa de acuerdo a esas obligaciones o pautas. La segunda modalidad de capital social está referida al potencial de información inherente a las relaciones sociales; la información es una base importante para la acción, que consigue quien es miembro de redes sociales. La tercera modalidad de capital social son los valores y las sanciones efectivas de la sociedad a sus miembros, de acuerdo al cumplimiento de los mismos. Cuando una sociedad tiene abundante capital social, se facilitan las relaciones de los miembros, aumentan las actividades productivas, se combate la pobreza y se produce desarrollo humano.

Las prácticas que generan capital social son aquellas que encarnan los valores de la ética civil, es decir, prácticas que potencian la autonomía personal, las relaciones horizontales, el respeto entre los actores; esas prácticas resultan beneficiosas para el conjunto de la sociedad, para el bien público, puesto que generan hábitos de confianza y solidaridad:

Sin recursos sociales, sin valores compartidos, sin hábitos que generan la confianza necesaria para firmar un contrato con ciertas garantías de cumplimiento, sin alguna dosis de honradez y lealtad, sin esa densa trama de asociaciones civiles que componen en realidad la más fecunda riqueza de las naciones y de los pueblos. Si falta capital social, no hay ni siquiera negocios en este mundo globalizado, en el que la red protectora de los valores y las asociaciones presta el suelo indispensable para que funcionen bien las transacciones y los contratos (Cortina, 2001, 98).

Viendo las prácticas de los países de la Unión Europea en la protección social y, de algunos países, en la cooperación internacional, quizás podamos acariciar el sueño europeo de una sociedad justa y eficiente para sus propios ciudadanos y para los inmigrantes. Jalones de ese sueño son el empleo estable, aunque flexible, la atención sanitaria proporcionada por una red pública desde una gestión pública, eficiente y equitativa, la educación de calidad con un reparto equitativo de la misma, la confianza de encontrar una red protectora en el momento de decir adiós a un trabajo remunerado y en la ancianidad, la garantía de encontrar el buen trato que merece todo humano, ya sólo por serlo, cuando el hambre y la miseria obligan a abandonar el propio país. 


\section{LÍNEAS DE PRÁCTICAS MORALES PARA LA EDUCACIÓN ANTE LA POBREZA}

\subsection{Desarrollo sostenible}

La primera de ellas, son aquellas prácticas orientadas a la educación para el desarrollo sostenible. La sostenibilidad, como la misma palabra indica, significa capaz de sostenerse y desarrollo sostenible es aquel que renuncia tanto a las aplicaciones científicas y tecnológicas incompatibles con el funcionamiento indefinido del sistema biosférico como también el que renuncia al regreso encubierto a la falta de desarrollo. Por supuesto, la cuestión del cambio de las actitudes personales y la modificación de las escalas de valores para instaurar el nuevo orden sostenible son determinantes, como siempre lo han sido en cada ocasión histórica en que se han subvertido los patrones económicos o sociales (Folch, 1998). Y al fomento de esas nuevas actitudes y valores tendrá que atender el diseño de las prácticas educativas.

El desarrollo sostenible es un nuevo concepto por el que se expresa la convicción de que el modelo actual de desarrollo está agotado, desde la perspectiva del bien de la humanidad y el deseo razonable de progreso de los países más pobres. La sostenibilidad implica equilibrio ecológico, social y económico lo que incide, al igual que el concepto de desarrollo, en la diferenciación respecto a las políticas que buscan sólo el crecimiento económico. Encontrar equidad y equilibrio de costes y beneficios entre la situación de la naturaleza, la producción económica y la distribución social justa de la renta responde bien a lo que se entiende hoy por desarrollo sostenible (Colom, 2000).

Es necesaria la construcción de una nueva cultura del medio ambiente y unas nuevas relaciones socioeconómicas, tanto a nivel planetario como dentro de los Estados, en el marco de una concertación civil, que apuesten por el desarrollo sostenible. El cambio de enfoque y, especialmente, su aplicación práctica, no son un ajuste de cuentas con el pasado ni con el presente, sino un reajuste de los desajustes en los que vivimos; una decisión de sensatez científica y social para garantizar la paz y el futuro de la humanidad. La cultura de la sostenibilidad comporta la adopción fuerte de los valores morales de la justicia y la solidaridad. Por lo que el desarrollo sostenible es fundamentalmente un proyecto moral (Ortega y Mínguez, 2003). Las prácticas sociales de la escuela que llevan a respetar la naturaleza, la identidad personal, las formas de vida, las costumbres y las creencias de los estudiantes, con origen en diferentes pueblos y grupos sociales, así como la promoción de relaciones de convivencia entre ellos, están configurando la personalidad moral de los participantes y contribuyendo a la minoración de las diferencias en cuanto a capacidades de desarrollo, con frecuencia producidas por la pobreza (Aznar, 2002, 2003). Con tales prácticas educativas para el desarrollo sostenible:

Se debe propiciar una ética diferente en relación con lo económico. Si tenemos en cuenta la pobreza y las diferencias en cuanto a calidad de vida, la inconsciencia económica o el consumo innecesario, lo económico se convierte en un problema moral serio y grave que debe solucionarse en el ámbito escolar y familiar y, con el 
tiempo, en el seno de la sociedad misma; lo económico, pues, como una variable moral de primera magnitud que deberá equilibrar producción y necesidad, acumulación y equidad. Paralelamente, cabría hablar de los valores culturales, de la necesidad moral de su supervivencia (Colom, 2000, 111-112).

\subsection{La cooperación internacional}

La segunda línea de prácticas de educación moral tendría que centrarse en la cooperación internacional para el desarrollo de los pueblos, que se legitima desde el valor fundamental de la ética: la dignidad de la persona. La dignidad de toda persona y el valor de la vida exigen el compromiso ético de olvidar egoísmos e insolidaridades y de enfrentarse a la violencia de la muerte. Amar la vida es luchar por las condiciones de su posibilidad, cuando se ven afectadas o se quiebran en algún lugar del mundo. La cooperación para el desarrollo de los pueblos es una expresión de ese movimiento por la vida, puesto que la miseria y el hambre producen millones de muertos.

La cooperación para el desarrollo de los pueblos ha tenido históricamente tres referentes. El primero es la cooperación para el crecimiento económico, y así el desarrollo ha estado vinculado al crecimiento productivo. Sin crecimiento económico acelerado, no son posibles ni el desarrollo ni la eliminación de la pobreza. El desarrollo, desde este punto de vista, está asociado esencialmente a la modernización tecnológica de los países con los que se colabora, por lo que es necesaria la transferencia de conocimientos y patentes como bienes fundamentales de la cooperación.

El segundo referente del desarrollo es el crecimiento económico con equidad social; no basta con crecer, sino que es preciso distribuir para atender a las necesidades básicas de todos los ciudadanos. La productividad sólo tiene sentido ético si es un camino hacia la equidad. Sólo la modernización productiva, con justicia social, manifiesta el desarrollo de los pueblos. La ayuda internacional, desde este planteamiento, puede tener un poder disuasorio, entendido como el principio de condicionalidad: se ayuda a aquellos países que se comprometen a modificar radicalmente las estructuras políticas y económicas para que los beneficios lleguen a todos los ciudadanos, especialmente a los más pobres. La gobernabilidad ${ }^{4}$ es tal vez el factor más importante para erradicar la pobreza y promover desarrollo:

4. “Una gobernabilidad desde la perspectiva del desarrollo humano es una gobernabilidad democrática. Se vela por conseguir que: se respeten los derechos humanos y las libertades fundamentales de las personas, permitiéndoles vivir con dignidad; las personas participen en la toma de decisiones que afectan a sus vidas; que se pueda exigir responsabilidad a los encargados de la toma de decisiones; las interacciones sociales se vean regidas por programas, instituciones y prácticas globales y justas; exista igualdad entre hombres y mujeres en las esferas privada y pública, y en la toma de decisiones; que no exista discriminación por motivos de raza, origen étnico, clase, género o cualquier otro atributo; las necesidades de las generaciones futuras se reflejen en las políticas actuales; las políticas económicas y sociales respondan a las necesidades y a las aspiraciones de los pueblos; el objetivo de las políticas 
Existe un concepto erróneo, muy extendido, en el sentido de que el desarrollo humano trata únicamente de resultados económicos y sociales, tales como reducir la pobreza y mejorar la salud y la educación. Aunque estos resultados son importantes para el desarrollo humano, su objetivo es mucho más amplio: fomentar la libertad, el bienestar y la dignidad de la persona en todas partes (PNUD, 2002, 52-53).

En la actualidad, el desarrollo se entiende preferentemente como el proceso de expansión de las capacidades humanas, tanto individuales como comunitarias (Sen, 2000). El principio de condicionalidad ha sido sustituido por el principio de responsabilidad compartida. Así, la cooperación para el desarrollo es entendida como la puesta en práctica de proyectos que se ejecutan en común por los donantes y por quienes reciben la ayuda. El acento se pone en que los países que reciben ayuda internacional desarrollen las capacidades personales y productivas de sus miembros, mediante la educación y la salud, y profundicen en los cambios políticos necesarios para el ejercicio de las libertades públicas.

Las prácticas educativas para la cooperación al desarrollo de los pueblos tienen que centrarse en cuatro líneas de acción: la deliberación sobre que la cooperación se legitima desde razones de justicia; el fomento del cosmopolitismo; la persuasión de que los bienes de la tierra son bienes sociales y la visión internacionalista de los problemas.

La deliberación sobre la cooperación internacional, desde la perspectiva de la justicia, lleva al descubrimiento de las trampas que, a veces, se encuentran detrás de tan hermosa declaración: los intereses de política exterior y de seguridad o simplemente los intereses económicos de los países donantes (Zamora, 1999). Ello invita a fortalecer en los estudiantes las capacidades de la deliberación ética para no caer en la trampa de las grandes palabras. La ética tiene que estar en el centro de la cooperación para el desarrollo (Goulet, 1999). El hecho incontrovertible e importante es que la gente muere de hambre y de enfermedades, cuando el hambre y esas enfermedades son evitables, y ésa es una situación de violencia estructural que los países ricos ejercen sobre los países pobres, al menos indirectamente.

El proyecto de forjar una ciudadanía cosmopolita puede convertir al conjunto de los seres humanos en una comunidad. Se abre paso la postura de quienes defienden como necesaria la formación de identidades morales individuales, nuevas y complejas, que respondan a un ideal de ciudadanía múltiple: personas que se vean como miembros de una comunidad étnica, local o nacional, pero también como seres humanos con responsabilidades sobre todos los demás. La democracia del futuro debe permitir a los ciudadanos cosmopolitas ganar importancia como mediadores entre tradiciones culturales y discursos diferentes, buscando significados compartidos que posibiliten el entendimiento de las gentes y de los pueblos (Held, McGrew, Goldblatt y Perraton, 1999).

económicas y sociales sea la erradicación de la pobreza y la ampliación de las oportunidades que las personas tengan en sus vidas». (Fuente: Oficina del Informe sobre Desarrollo Humano). 
Los bienes de la tierra son bienes sociales que tienen que ser socialmente distribuidos. Y no sólo en un país, sino en el conjunto de la humanidad, que a fin de cuentas es la que los produce (Cortina, 2001, 2003); la interdependencia es la clave de la producción, aunque personas y países sigan aferrados a la falsa ideología del individualismo posesivo, sigan convencidos que los productos son suyos. Walzer (1993) enumera, en Las esferas de la justicia, doce bienes, que tendrían que ser compartidos por todos los habitantes de nuestro planeta: la pertenencia a una comunidad política, la educación, la seguridad y el bienestar, el dinero y los productos del mercado, los cargos y puestos de responsabilidad, el trabajo, el tiempo libre, el poder político, la autoestima, los beneficios de la tecnología, el reconocimiento social, la igualdad; todos estos bienes podrían articularse en lo que se puede llamar las condiciones de la libertad que permiten el desarrollo de las capacidades de las personas para llevar adelante una vida feliz.

En una aldea global, el egoísmo es una actitud pasada de moda como lo son las pequeñas endogamias, los vulgares nepotismos, la defensa de los míos, los nuestros, sea en la política, en la economía, en la universidad o en el hospital. Ante retos universales, no cabe sino la respuesta de una actitud ética universalista que tenga por horizonte, para la toma decisiones, el bien universal, aunque sea preciso construirlo desde el bien local. Es necesaria una educación de talante mundialista: para ser integrante de una sola nación, el planeta, habitada por unos seres con igualdad de derechos y deberes: la humanidad, sin ningún tipo de exclusiones (Colom, 2000).

\subsection{El consumo justo y responsable}

La tercera línea de prácticas morales tiene que relacionarse con la característica más definitoria de la sociedad de nuestro tiempo: el consumo. La educación moral ante la pobreza exige la austeridad de quienes vivimos en los países desarrollados, personas e instituciones. No pretendemos decir que no se consuma; el consumo puede entenderse como un medio de desarrollo humano cuando no afecta negativamente al bienestar de los otros, es justo para las generaciones futuras, respeta la capacidad del planeta y estimula el surgimiento de comunidades productivas y creativas. Lo verdaderamente inmoral es el consumo superfluo y exhibicionista, que genera la exclusión y la humillación de quienes no satisfacen sus necesidades básicas.

La ética kantiana estableció la regla de oro con la célebre formulación del imperativo categórico: "Obra de tal manera que la máxima de tu actuación pueda convertirse por tu voluntad en ley universal de la naturalezan; según tal ética, cualquier norma que pretenda tener valor moral debe ser formalmente universalizable. Si los ciudadanos de todos los países tuvieran estilos de vida semejantes a los ciudadanos de los países desarrollados, el consumo esquilmaría los recursos de la tierra y haría la vida inviable para las generaciones futuras. En el caso del consumo no cabe hacer excepciones, referidas a unos grupos de personas o a unos países, 
porque si la universalización de una norma de consumo destruye los recursos naturales entonces es inmoral. Si aceptamos la regla de oro y se aplica al consumo, la norma moral del consumidor puede formularse así: "Consume de tal modo que tu norma sea universalizable sin poner en peligro el mantenimiento de la naturaleza" y una segunda formulación diría: "Consume de tal modo que respetes y promuevas la libertad de todo ser humano, tanto en tu persona como en la de cualquier otra, siempre al mismo tiempo" (Cortina, 2002). Ante la pobreza que nos revelan los datos de los informes internacionales (PNUD, 2002, 2003; Eurostat, 2002, Cobo, 2001), las pautas de consumo de los ciudadanos de los países desarrollados son inmorales.

Para un consumo justo y responsable es necesario fomentar en los estudiantes estilos de vida sostenibles, asumibles y universalizables. Para ello, conviene proceder en una doble dirección: averiguar los estilos de vida que producen daño social y exclusión a personas y a pueblos y que deberían estar prohibidos en una sociedad que se pretenda justa; $y$, por otro lado, los estilos de vida que fomentan las capacidades personales y son respetuosos con el medio ambiente.

Dos son las competencias a formar en los estudiantes: la lucidez y la prudencia. La lucidez para desentrañar los motivos por los que consumen y los mecanismos sociales que les avivan el deseo de consumir diferentes productos. Es difícil combatir la creencia por la que se identifica la autorrealización con el éxito expresado en la posesión de objetos costosos, la convicción generalizada de que lo natural es consumir de forma creciente y que moderar el consumo es una forma de retroceso. Por ello, la lucidez para buscar otras formas de autorrealización personal y de desarrollo de capacidades personales es una buena meta educativa. La prudencia, por su parte, muestra que la calidad de vida debería prevalecer sobre la cantidad de bienes (Nussbaum y Sen, 1993). Tiene importancia educativa que los estudiantes descubran que la vida buena, la vida feliz, no depende tanto del consumo ilimitado de productos del mercado como de unas relaciones humanas satisfactorias, del disfrute de la naturaleza, del sosiego y el disfrute del tiempo.

Pero la austeridad, la lucidez y la prudencia que hemos mencionado, como competencias a desarrollar en los estudiantes, tienen que estar al servicio del principio moral de la justicia: no vivimos solos sino en compañía de quienes mueren de hambre y de enfermedades evitables, impedidos en su potencial desarrollo de capacidades humanas, quienes teniendo derecho al disfrute de los bienes, para su permanencia en la vida y para el desarrollo de sus capacidades, se les niega por quienes despilfarran los bienes comunes. La responsabilidad por los pobres y los excluidos adquiere la fuerza de un imperativo moral incondicionado:

La vulnerabilidad y precariedad de todo lo vivo, que nos demanda el "cuidado", se hace urgente apelación en las personas que necesitan de nuestras acciones para garantizar su existencia, y una existencia digna, porque tenemos la comunidad de lo humano con ellas. En cada persona individual está contenida la dignidad de toda la humanidad (tal es el significado de la expresión kantiana "la persona es fin en sí misma y no tiene un valor de cambio" para conseguir otra cosa), por lo que sus 
demandas a la existencia, en condiciones justas, son derechos que, a su vez, constituyen exigencias concretas para nuestro deber y nuestro sentimiento del deber. La ética de la responsabilidad es el deber comprometido para actuar hasta donde alcanza nuestro poder de hacerlo (Escámez y Gil, 2001, 34).

Esa responsabilidad tiene que ser ejercida desde prácticas sociales que presentan alternativas u operan dentro del sistema económico, siempre que produzcan cambios en las situaciones injustas. Una de tales prácticas, que se abre paso con vigor, es el llamado Comercio Justo. Consiste en comprar los productos, que se necesitan, a aquellas empresas que cumplen con determinados valores éticos y, sobre todo, en tomar el control de los ahorros para depositarlos en aquellas entidades financieras que se comprometen con programas de desarrollo humano. Los criterios pueden ser también negativos, como no comprar productos o no depositar los ahorros en empresas que invierten en armas o emplean niños o se dedican a la pornografía (Sanz, 2003). Una forma de educación para el Comercio Justo consiste en proporcionar información y debate sobre todas las alternativas posibles que se presentan en la sociedad para que los estudiantes puedan ir decidiendo cada vez más responsablemente.

\subsection{La participación en movimientos de servicio voluntario a la sociedad}

La cuarta línea de prácticas morales se refiere a la participación de los estudiantes en movimientos de servicio voluntario a la sociedad. Lo que caracteriza a los nuevos movimientos sociales es la conquista de nuevas oportunidades para participar en las decisiones que afectan a los ciudadanos mediante la democracia directa o dando un mayor protagonismo a los grupos de autoayuda y a formas cooperativas de organización social. Un rasgo distintivo de los nuevos movimientos sociales es que no defienden los intereses específicos de un grupo social ni se nutren de las capas sociales desfavorecidas. Sus motivaciones son la defensa de los bienes colectivos, no los exclusivos de los miembros del grupo. Prefieren una estructura descentralizada, abierta y democrática, frente a la estructura centralizada y jerárquica de los viejos movimientos sociales. Reivindican para sí una intencionada acción social y política al margen del marco institucional de las administraciones públicas. Esos movimientos sociales reivindican la esfera de la acción política, en el interior de la sociedad civil, como su espacio propio desde el que cuestionar las prácticas e instituciones, tanto mercantiles como gubernamentales:

En la actualidad, desde Bosnia hasta Ruanda, la moral de emergencia se vuelve contra las víctimas. Éstas son consideradas sólo desde el punto de vista de la miseria inmediata. Ya no se trata de personas, de ciudadanos que luchan para defender determinados valores o simplemente para alcanzar el derecho a vivir, sino de estómagos que alimentar, siempre y cuando consigan sobrevivir... La exclusividad humanitaria desempeña cada vez más una función de amnésico, impide cualquier análisis político de la situación (Médicos sin Fronteras, 1995, xx). 
La ética de la responsabilidad exige el compromiso con la transformación de los escenarios sociales en los que se producen las relaciones reales de las personas y las condiciones políticas y económicas que provocan la pobreza y la injusta exclusión de las personas y de los países. La ética de la responsabilidad obliga a la acción, que es la única facultad que tenemos para producir los cambios políticos y sociales necesarios, formando colectivos y participando en las organizaciones y movimientos ciudadanos para que las acciones tengan posibilidades de éxito.

Las prácticas sociales, que se diseñan en la escuela, producen aprendizajes morales y conforman la personalidad moral cuando vinculan los currículos escolares a la adquisición por los estudiantes de competencias ciudadanas para la participación en los asuntos de la comunidad. De ese modo, las prácticas morales, que se diseñan en la escuela, educan moralmente a la vez que producen una reforma de la sociedad; y la participación del estudiante, como ciudadano, es un procedimiento básico del aprendizaje de tales competencias y no una actividad complementaria que se desarrolla al margen o paralela al currículum escolar.

\subsection{La formación de competencias para la participación política}

La quinta línea de prácticas morales está centrada en la formación de competencias de los estudiantes para su intervención como agentes en la vida pública de sus países (Escámez, 2003). La participación responsable en la sociedad civil exige que los ciudadanos adquieran las competencias necesarias para pedir razones de las propuestas de los otros ciudadanos, dar razones de las propias propuestas, deliberar sobre las consecuencias que de unas y otras se derivan para el bien común, decidir los proyectos de acción y tener la fuerza y perseverancia de llevar a cabo tales proyectos de acción, a pesar de las dificultades u obstáculos que puedan presentarse. También la participación responsable en la sociedad civil exige la preparación de los ciudadanos para que pidan a los gobiernos las razones o justificación de sus políticas públicas.

Se entiende por discurso público el ejercicio de dar y pedir razones o argumentos a los demás sobre asuntos de los que se derivan efectos públicos. Desde esa perspectiva, el discurso público significa el que tiene como objeto el bien público; y también el procedimiento de hacerlo: la creación de un espacio en el que los ciudadanos pueden deliberar públicamente sobre aquello que les afecta. La existencia de esa esfera pública es una condición imprescindible de la ilustración de la ciudadanía y de la legitimación de las decisiones políticas (Cortina, 1997).

Entre las cualidades que tiene que tiene que reunir un discurso público para ser civilizado (Barber, 2000), conviene hacer referencia a que el discurso público civilizado es un diálogo compartido y supone la base para la acción de los que participan en él, convirtiendo a los interlocutores en agentes. Con el discurso público se trata de encontrar principios y estrategias de acción para la solución de los problemas comunes o el beneficio social, por lo que tiene que ser un discurso responsable. 
El discurso público, que conforma opinión pública, es una forma de poder de la sociedad civil para establecer la agenda para una acción común por la que una comunidad política puede perseguir sus intereses o atacar y presionar a un Gobierno irresponsable. Por ello, es fundamental que los estudiantes alcancen las competencias para participar en esos discursos.

La gestión para el desarrollo humano y la lucha contra la pobreza no puede dejarse en manos de gobiernos incompetentes o irresponsables. Debe también ocuparse de si las instituciones públicas, y las normas que promulgan, son justas y si todos los ciudadanos tienen voz en determinar cómo funcionan. Se sabe mucho de las políticas económicas y sociales que ayudan a erradicar la pobreza. Pero pocos países aplican dichas políticas, a menudo porque los posibles beneficiarios, los pobres, carecen de capacidades desarrolladas para la defensa de sus intereses. Por ello, es importante la educación para la promoción de una participación más amplia en las instituciones y en las normas que afectan la vida de las personas, con el fin de asegurar resultados económicos y sociales más equitativos.

Las capacidades para participar en la vida de la comunidad política son tan importantes para el desarrollo humano como la capacidad de leer y escribir o de disfrutar de buena salud. Ser capaz de participar en la vida pública, obteniendo respeto y teniendo voz en las decisiones comunitarias, es fundamental para el desarrollo de un país. El primer informe sobre desarrollo humano, en 1990, subrayaba, como estrategias fundamentales para el desarrollo, la necesidad de invertir en educación y salud y fomentar un crecimiento económico equitativo. Pero en el informe se destaca un tercer pilar para el desarrollo humano del siglo xxi: promover la participación mediante la gestión democrática de los asuntos públicos. La participación fomenta la acción colectiva e individual y es un motor de progreso para los temas esenciales de desarrollo humano como la erradicación de la pobreza:

Las personas que están mejor educadas y son también libres tienen más posibilidades de exigir políticas que se ajusten a sus necesidades y respondan a las prioridades del desarrollo humano (PNUD, 2002, 53).

\section{CONCLUSIONES}

En el presente trabajo hemos presentado la educación moral como formación de competencias en los estudiantes para que intervengan en la solución de los problemas de justicia que se producen en nuestra sociedad y en la comunidad internacional; en concreto, hemos llamado la atención sobre la injusticia de la pobreza extrema en la que malviven y mueren miles de millones de personas. Hemos defendido, siguiendo grandes tradiciones del pensamiento liberal y comunitarista, que la educación moral tiene como objetivo central la formación de los estudiantes para la acción en la vida pública; la situación de pobreza extrema en nuestro tiempo tiene que ser combatida y resuelta desde los gobiernos nacionales y la cooperación de la 
comunidad internacional, pero tal actuación institucional no se producirá sin la acción de ciudadanos organizados y competentes que pidan cuentas y presionen a los líderes de los gobiernos nacionales y de las instituciones internacionales o los combatan cuando son incompetentes o irresponsables o persigan sólo sus intereses individuales. Hemos argumentado seis propuestas pedagógicas, que los profesores pueden diseñar, estimular y facilitar como prácticas morales de los estudiantes, para adquirir competencias morales a la vez que colaboran en la moralización de los distintos contextos sociales que viven cotidianamente.

\section{BIBLIOGRAFÍA}

AzNAR, P. (2002) La escuela y el desarrollo humano sostenible: retos educativos a nivel local, Teoría de la Educación, 14, 151-183.

- (2003) Participación de las agencias educativas en el desarrollo sostenible a nivel local: hacia una agenda 21 escolar, Revista Española de Pedagogia, 225, 223-242.

BARBER, B. R. (2000) Un lugar para todos. Cómo fortalecer la democracia y la sociedad civil. Barcelona, Paidós.

BERNAL, A. (2003) El constructo "madurez personal" como competencia y sus posibilismos pedagógicos, Revista Española de Pedagogía, 225, 243-262.

Cardenal, R. (1999) la cooperación con las víctimas y los pobres, en Ortega, P. y Míngle:, R. (coords.). Educación, cooperación y desarrollo. Murcia, Caja Murcia, 157-168.

Сово, J. M. (2001) Educación ética y nueva sociedad, Revista de Educación, número extraordinario, 289-315.

Colom, A. J. (2000) Desarrollo sostenible y educación para el desarrollo. Barcelona, Octaedro.

Cortina, A. (1997) Ciudadanos del mundo. Hacia una teoria de la ciudadanía. Madrid, Alianza.

- (2001) Alianza y contrato. Política, ética y religión. Madrid, Trotta.

- (2002) Por una ética del consumo. Madrid, Taurus.

- (2003) El quehacer público de la ética aplicada, en Cortina, A. y GarCíA-MARZর̄, D. (eds.). Razón pública y éticas aplicadas. Los caminos de la razón práctica en una sociedad pluralista. Madrid, Tecnos, 13-44.

Cortina, A.; Escámez, J. y PÉrez-Delgado, E. (1996) Un mundo de valores. Valencia, Generalitat. EsCámeZ, J. (2003) La educación para la participación en la sociedad civil, Revista de Educación, número extraordinario, 191-211.

EsCÁMEZ, J. y GIL, R. (2001) La educación en la responsabilidad. Barcelona, Paidós.

EUROESTAT-COMISION EUROPÉENNE (2002) La situation social dans l'Union Européenne. Bruxelles.

Folch, R. (1998) Ambiente, emoción y ética. Actitudes ante la cultura de la sostenibilidad. Barcelona, Ariel.

GIDDENS, A. (1995a) La constitución de la sociedad. Bases para la teoría de la estructuración. Buenos Aires, Amorrortu.

- (1995b) Modernidad e identidad del yo. Barcelona, Península.

GoulET, D. (1999) Ética del desarrollo. Madrid, IEPALA.

HABERMAS, J. (1991) Escritos sobre moralidad y eticidad. Barcelona, Paidós. 
Held, D. A.; MCGRew, D.; Goldblatt, D. y Perraton, J. (eds.) (1999) Global Transformations. Stanford University Press.

HerReros, F. y De Francisco, A. (2001) Introducción: el capital social como programa de investigación, Zona Abierta, 94-95, 1-46.

KOHLBERG, L. (1981) Essays on moral development. The philosophy of moral development. San Francisco, Harper and Row.

MACINTYRE, A. (1987) Tras la virtud. Barcelona, Crítica.

- (1992) Tres versiones rivales de la ética. Madrid, Rialp.

- (1994) Justicia y racionalidad. Barcelona, Eiunsa.

MarTínez, E. (2002) Aporofobia, en Conill, J. (coord.). Glosario para una sociedad intercultural. Valencia, Bancaja, 17-23.

MÉdicos Sin Fronteras (1995) Poblaciones en peligro 1995. Informe anual sobre la acción bumanitaria en los territorios de crisis. Madrid, Acento.

NAïr, S. (2003) Los que vienen aquí, El País, 26 de diciembre.

Naval, C. (1995) Educar ciudadanos. La polémica liberal-comunitarista en educación. Pamplona, Eunsa.

Nussbaum, M. y Sen, A. (1993) The Quality of Life. Oxford, Clarendon Press.

Ortega, P. y Mínguez, R. (2003) Educar para una cultura medioambiental, Revista de Educación, número extraordinario, 271-294.

PNUD (2002) Informe sobre Desarrollo Humano. Profundizar la democracia en un mundo fragmentado. Madrid, Mundi-Prensa.

- (2003) Informe sobre Desarrollo Humano. Los objetivos de desarrollo del Milenio: un Pacto entre las naciones para eliminar la pobreza. Madrid, Mundi-Prensa.

PuIG, J. M. (1996) La construcción de la personalidad moral. Barcelona, Paidós.

- (2003) Prácticas morales. Una aproximación a la educación moral. Barcelona, Paidós.

SEN, A. (2000) Desarrollo y libertad. Barcelona, Paidós.

ReBoul, O. (1999) Los valores de la educación. Barcelona, Idea Books.

SANZ, F. (2003) Educar para el desarrollo sostenible y el comercio justo. Revista de Educación, número extraordinario, 241-294.

Stigliztz, J. E. (2004) La globalización y sus quejas en 2004, El País 6 de enero.

SuÁreZ del Toro, J. M. (2003) Entrevista, País semanal, 1422, 14-20.

WALZER, M. (1993) Las esferas de la justicia. México, FCE.

ZAmora, J. A. (1999) Dimensión ética de la cooperación al desarrollo, en OrTEGA, P. y MínguEz, R. (coords.). Educación, cooperación y desarrollo. Murcia, Caja Murcia, 77-121. 